\title{
Schwann Cell-Derived Factors Modulate Synaptic Activities at Developing Neuromuscular Synapses
}

\author{
Guan Cao and Chien-Ping Ko \\ Section of Neurobiology, Department of Biological Sciences, University of Southern California, Los Angeles, California 90089-2520
}

\begin{abstract}
Glial cells are active participants in the function, formation, and maintenance of the chemical synapse. To investigate the molecular basis of neuron-glia interactions at the peripheral synapse, we examined whether and how Schwann cell-derived factors modulate synaptic function at developing neuromuscular junctions (NMJs). Schwann cell-conditioned medium (SC-CM) from Xenopus Schwann cell cultures was collected and applied to Xenopus nerve-muscle cocultures. We found that SC-CM increased the frequency of spontaneous synaptic currents (SSCs) within 3-15 min by an average of $\sim 150$-fold at developing neuromuscular synapses. The increase in SSC frequency by SC-CM is a presynaptic effect independent of neuronal excitability and requires the influx of $\mathrm{Ca}^{2+}$. In contrast to its potentiating effect on spontaneous transmitter release, SC-CM suppressed the evoked transmitter release. The SC-CM effect required the presence of motoneuron soma but not protein synthesis. Using molecular weight cutoff filters and dialysis membranes, we found that the molecular weight of functional factor(s) in SC-CM was within 500 and $5000 \mathrm{Da}$. The SC-CM effect was not attributable to currently known factors that modulate synaptic efficacy, including neurotrophins, glutamate, and ATP. SC-CM also enhanced spontaneous synaptic release at developing NMJs in Xenopus tadpoles in situ. Our results suggest that Schwann cells release small molecules that enhance spontaneous synaptic activities acutely and potently at developing neuromuscular synapses, and the glial cell-enhanced spontaneous neurotransmission may contribute to synaptogenesis.
\end{abstract}

Key words: glia; neuromuscular junctions; neuron-glia interactions; Schwann cell; synaptic transmission; synaptogenesis

\section{Introduction}

After being considered passive and supportive elements in the nervous system for decades, glial cells have emerged recently as an active and essential partner in forming the "tripartite" synapse with the presynaptic nerve terminal and the postsynaptic specialization (Araque et al., 1999; Volterra et al., 2002). Glial cells can detect neuronal activity and modulate synaptic function, as well as promote synapse formation, repair, and stabilization (Haydon, 2001; Fields and Stevens-Graham, 2002; Auld and Robitaille, 2003; Hatton and Parpura, 2004; Allen and Barres, 2005; Ko et al., 2007). To understand how the chemical synapse works and forms, it is thus essential to elucidate the molecular mechanisms of synapse-glial interactions.

Perisynaptic Schwann cells (PSCs) (also known as terminal Schwann cells) are the peripheral glial cells that cap the nerve terminal at the neuromuscular junction (NMJ). PSCs have been demonstrated to play multiple roles in synapse function, mainte-

\footnotetext{
Received March 25, 2007; revised May 7, 2007; accepted May 13, 2007.

This work was supported by National Institutes of Health Grant NS17954 and a Muscular Dystrophy Association research grant. We are grateful to Drs. W. L. Byerly, J. Wan, and M.-M. Poo for help with patch-clamp recording techniques, and Z. Feng for help with Xenopus Schwann cell culture. We also thank Drs. W. L. Byerly, A. A. Herrera, M.-M. Poo, J. Walsh, and S.-Y. Yin, and members of the Ko laboratory, L. V. Reddy, J. Yang, Z. Feng, and Y. Sugiura for their critical comments.

Correspondence should be addressed to Dr. Chien-Ping Ko, Section of Neurobiology, Department of Biological Sciences, University of Southern California, Los Angeles, CA 90089-2520. E-mail: cko@usc.edu.

G. Cao's present address: Department of Cellular and Molecular Physiology, School of Medicine, Yale University, New Haven, СТ 06520.

D01:10.1523/JNEUROSCI.1329-07.2007

Copyright $\odot 2007$ Society for Neuroscience $\quad$ 0270-6474/07/276712-11\$15.00/0
}

nance, repair, and formation (Auld and Robitaille, 2003; Kang et al., 2003; Koirala et al., 2003; Feng et al., 2005; Feng and Ko, 2007; Ko et al., 2007). For example, adult PSCs can detect evoked synaptic activities by elevating intracellular $\mathrm{Ca}^{2+}$ levels (Jahromi et al., 1992; Reist and Smith, 1992; Rochon et al., 2001) and are capable of modulating synaptic transmission when $\mathrm{Ca}^{2+}$ concentration or the G-protein signaling in PSCs is altered (Robitaille, 1998; Castonguay and Robitaille, 2001; Rochon et al., 2001). PSCs can also play a long-term maintenance role in the structure and function of adult NMJs, as demonstrated by the retraction of nerve terminals and reduction in synaptic efficacy seen 1 week after PSC ablation (Reddy et al., 2003). After nerve injury, adult PSCs sprout extensive processes (Reynolds and Woolf, 1992) that guide regenerating nerve terminals (Son and Thompson, 1995a,b; O'Malley et al., 1999; Koirala et al., 2000; Kang et al., 2003; Hayworth et al., 2006). A similar guiding role is also seen at developing NMJs in which PSCs grow ahead of nerve terminal extension in tadpole muscles, but nerve terminals retract or stop extension after PSC ablation (Herrera et al., 2000; Reddy et al., 2003). These results suggest that PSCs also promote synaptic growth and are essential for synaptic maintenance at developing NMJs.

The molecular mechanisms of synapse-glia interactions at the NMJ are not well understood. To investigate how Schwann cells promote synaptogenesis, we have shown previously that Schwann cell-conditioned medium (SC-CM) can increase the number of nerve-muscle contacts in Xenopus tissue culture (Peng et al., 2003). However, it has been unclear whether 
Schwann cells promote synaptic function at developing NMJs. To address this question and to further understand the molecular basis of synapse-glia interactions, we studied the effects of SC-CM on transmitter release at developing frog NMJs in vitro and in vivo. Our findings indicate that Schwann cells release factors with small molecular weights between 500 and 5000 Da that markedly and acutely potentiate spontaneous synaptic release. We speculate that the enhancement of spontaneous synaptic transmission by glial cells may contribute to the formation and stability of developing synapses.

\section{Materials and Methods}

Adult Xenopus Schwann cell culture

Sciatic nerves were dissected from adult Xenopus laevis, and epineurial membranes were removed. Nerves were cut into small pieces $(\sim 2 \mathrm{~mm})$ and digested with $0.3 \%$ collagenase and $0.25 \%$ trypsin-EDTA (Invitrogen, Carlsbad, CA) in $37^{\circ} \mathrm{C}$ for $30 \mathrm{~min}$. Dissociated cells were plated on laminin-1-coated culture dishes with culture medium consisting of $45 \%$ Leibovitz's L-15 medium (Invitrogen), 45\% Ringer's solution (in mм: $115 \mathrm{NaCl}, 2 \mathrm{CaCl}_{2}, 2.5 \mathrm{KCl}$, and 10 HEPES, pH 7.4), and $10 \%$ fetal bovine serum (Invitrogen). The culture medium was substituted with serumfree L-15/Ringer's solution (1:1, v/v) from the second week and subsequently changed once every week. The identity of Schwann cells in culture was verified by staining with monoclonal antibody 2A12 (Astrow et al., 1998) or anti-glial fibrillary acidic protein antibody (Georgiou et al., 1994). Schwann cell-conditioned medium was collected after $2-3$ weeks in culture.

\section{Embryonic Xenopus nerve-muscle culture}

The embryonic Xenopus nerve-muscle culture method was slightly modified from previously described protocols (Tabti and Poo, 1991). Briefly, the neural tubes and associated myotomal tissue were dissected out from 1-d-old Xenopus embryos (stage 22-24) (Nieuwkoop and Faber, 1994), dissociated in $\mathrm{Ca}^{2+}$ - and $\mathrm{Mg}^{2+}$-free Ringer's solution, plated on $35 \mathrm{~mm}$ tissue culture dishes, and incubated at room temperature $\left(20-22^{\circ} \mathrm{C}\right)$ for $1-2 \mathrm{~d}$ before the recording. The culture medium consisted of $50 \%$ of L-15 medium, $49 \%$ of Ringer's solution, $0.5 \%$ of fetal bovine serum, and $0.5 \%$ of insulin-transferrin-selenium-A supplement (Invitrogen).

\section{Electrophysiology}

Patch-clamp recording from myocytes in culture. Synaptic currents were recorded from singly innervated myocytes in 1- to 2-d-old nerve-muscle cultures by whole-cell perforated-patch recording method (Hamill et al., 1981; Wan and Poo, 1999), using a patch-clamp amplifier Axopatch 200B (Molecular Devices, Palo Alto, CA). The micropipette internal solution contained the following (in $\mathrm{mM}$ ): 125 potassium gluconate, 20 $\mathrm{KCl}, 1 \mathrm{NaCl}, 1 \mathrm{MgCl}_{2}$, and 10 HEPES, pH 7.2. The micropipette was immersed into normal perforated patch internal solution for $10 \mathrm{~s}$ and then filled with internal solution with the addition of amphotericin B ( $200 \mu \mathrm{g} / \mathrm{ml}$; Sigma, St. Louis, MO), which made it much easier to form a gigaohm seal on the myocyte surface. The whole-cell patch holding potential was $-70 \mathrm{mV}$. Signals were filtered at $5 \mathrm{kHz}$. Data was acquired using Axopatch 8.0 (Molecular Devices). The SC-CM was applied by perfusion using a peristaltic pump. Recordings from cells that were apparently damaged or in which the access resistance changed $>20 \%$ were discarded. All other recordings were stored in a computer and analyzed using the Mini Analysis program (Synaptosoft, Fort Lee, NJ). For the evoked synaptic currents (ESCs) recording, a patch electrode was loosely patched to the soma of the presynaptic neuron for the extracellular stimulation. ESCs were analyzed using Axopatch 8.0 software.

Intracellular recording from the pectoral muscle in Xenopus tadpoles. Xenopus tadpoles (stage 60-63) were anesthetized by immersion in $0.05 \%$ tricaine methanesulfonate (MS-222; Sigma, St. Louis, MO) in water. The chest skin was removed carefully, and the intact pectoral muscle was exposed. The heart was removed by a pair of forceps to avoid the vibration caused by the heart beating. The tadpoles were pinned on the Sylgard-coated dish. The intracellular recording electrode was filled with $3 \mathrm{~m}$ potassium acetate (pipette resistance, 60-80 M $\Omega$ ). The minia- ture endplate potentials (mEPPs) were recorded with pClamp 8 software (Molecular Devices) and analyzed with Mini Analysis software.

All chemicals for drug treatments, including ATP, glutamate, reactive blue 2 (RB2), staurosporine, nifedipine, $\omega$-conotoxin GVIA (CgTX), thapsigargin, anisomycin, tumor necrosis factor- $\alpha$ (TNF- $\alpha$ ), cholesterol, prostaglandin E2 (PGE2), and SC-19220 [1-acetyl-2-(8-chloro-10,11dihydrodibenz(b,f)(1,4)oxazepine-10-carbonyl hydrazine], were purchased from Sigma.

\section{$\mathrm{Ca}^{2+}$ imaging}

Stock solution (1 mM) of fura-2 AM (F1221; Invitrogen) was prepared with dimethylsulfoxide. Culture cells were loaded with fura-2 AM with a final concentration of $2 \mu \mathrm{M}$. After incubation for $30 \mathrm{~min}$, cultures were rinsed three times with normal culture medium (NCM) and incubated for another $30 \mathrm{~min}$ before taking the calcium images. Ratiometric calcium images were taken at two wavelengths, 340 and $380 \mathrm{~nm}$, and analyzed with InCytIm-2 software (Intracellular Imaging, Cincinnati, $\mathrm{OH}$ ).

\section{Results}

\section{Schwann cell-conditioned medium acutely increases} spontaneous synaptic release at developing neuromuscular junction in vitro

To study the role of Schwann cells in synaptic transmission at developing neuromuscular junctions, we examined the effect of Xenopus SC-CM on the synaptic efficacy of embryonic Xenopus NMJs. The serum-free SC-CM was collected weekly from 3- to 5-week-old Xenopus Schwann cell primary cultures. Spontaneous synaptic currents (SSCs) were recorded from singly innervated myocytes in 1-2 d old Xenopus tadpole nerve-muscle culture by perforated whole-cell, voltage-clamp recordings. SC-CM was applied via bath perfusion. We found that the SSC frequency began to increase gradually after $3-15 \mathrm{~min}$ in SC-CM (Fig. $1 A, B$ ); the frequency initially went up to a peak of 100 - to 500-fold of the control level and then maintained at an average of 80 - to 160 -fold of the control level. The average increase in SSC frequency was $\sim 150$-fold ( $150 \pm 47$, mean \pm SE; ranging from 10 - to 500 -fold; $n=22$ ) after 20-30 min of SC-CM treatment as summarized in Figure $1 C$. We also observed twitches in some myocytes (when they were not voltage clamped) treated with SC-CM, indicating that some of the SSCs might be suprathreshold. The potentiation of spontaneous synaptic release by SC-CM required the continuous presence of SC-CM, and it lasted for up to $2.5 \mathrm{~h}$, the longest period we recorded. The increase in SSC frequency by SC-CM was reversible and could be induced repeatedly at the same neuromuscular synapses.

To exclude the possibility that our findings on the effect of SC-CM resulted from an increase in osmolarity or $\mathrm{K}^{+}$concentration, which are known to increase transmitter release, we compared the osmolarity and $\mathrm{K}^{+}$concentration in SC-CM with those in NCM. The osmolarity of SC-CM $(\sim 285 \mathrm{mOsm} / \mathrm{kg})$ was slightly higher than that of NCM $(280 \mathrm{mOsm} / \mathrm{kg})$. However, this slight increase in osmolarity did not affect the synaptic transmission; we confirmed this by creating a modified NCM, adding sucrose to bring its osmolarity up to $285 \mathrm{mOsm} / \mathrm{kg}$. Furthermore, the time course of high-frequency spontaneous synaptic release induced by hypertonicity is different from that induced by SC$\mathrm{CM}$. The SSC frequency was enhanced immediately after increasing the bath solution osmolarity (data not shown), whereas it was enhanced gradually in SC-CM. Therefore, the increase in SSC frequency by SC-CM was not attributable to the high osmolarity. Nevertheless, we adjusted the osmolarity of all SC-CM with deionized water to $280 \mathrm{mOsm} / \mathrm{kg}$ before each experiment. We also measured the $\mathrm{pH}$ value of $\mathrm{SC}-\mathrm{CM}$, which stayed the same as that of NCM, pH 7.4. Furthermore, we measured the $\mathrm{K}^{+}$concentration in SC-CM and NCM with a $\mathrm{K}^{+}$-selective electrode and 
A

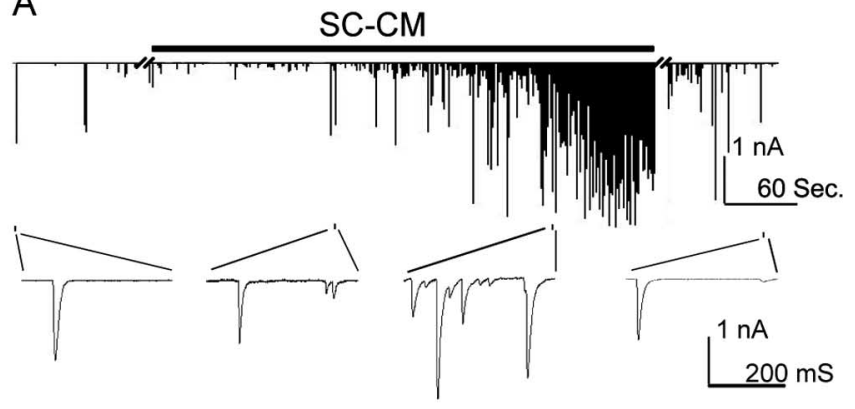

B

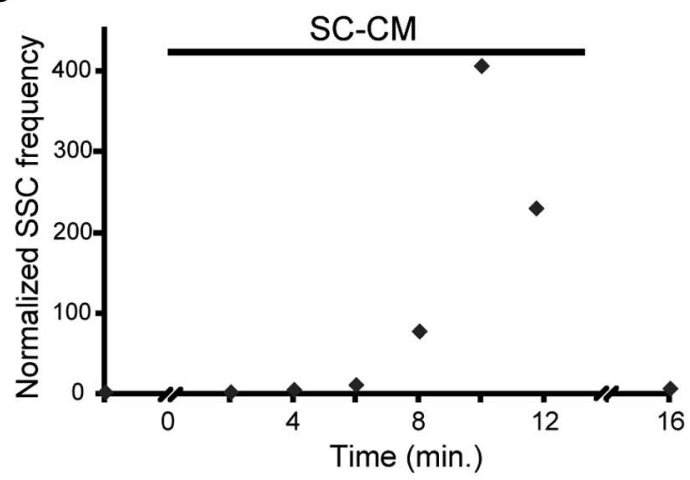

C

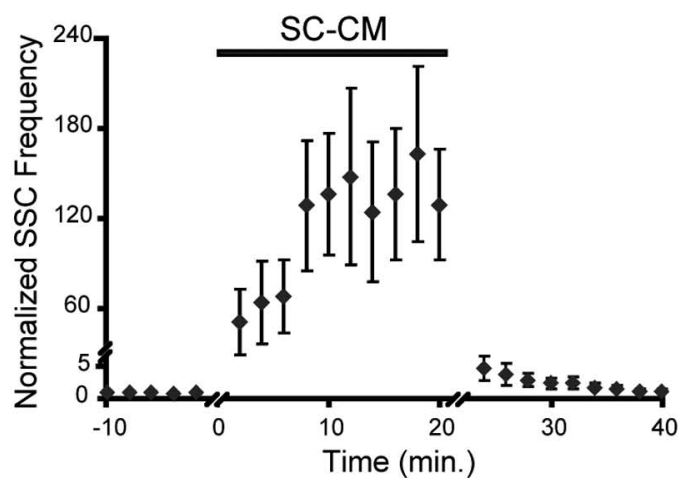

Figure 1. SC-CM increases the frequency of spontaneous synaptic release reversibly. $A, A n$ example of recordings depicting membrane currents recorded from a singly innervated myocyte using perforated-patch whole-cell recording method. SSCs are represented by downward deflections. The NCM is replaced with SC-CM during the period indicated by the horizontal bar. Samples of SSCS are shown below at higher time resolution. The SSC frequency began to increase $\sim 6 \mathrm{~min}$ after SC-CM was applied in this example and was restored after SC-CM was replaced with NCM. The line break (//) indicates an $\sim 2$ min break of changing solution by perfusion in this and the following figures. $\boldsymbol{B}$, The SSC frequency in $\boldsymbol{A}$ was quantified and normalized with the average SSC frequency in NCM. Each data point represents the SSC frequency during a 2 min period. SC-CM increased the SSC frequency gradually, and the increase was reversed after washout of SC-CM. Note that the SSC frequency surged initially to $\sim 400$-fold and then dropped by $\sim 50 \%$ in this example. The initial surge of SSC frequency during application of SC-CM has also been seen in other examples. C, Summary of 22 experiments shows the changes in SSC frequency (mean \pm SE) after the treatment of SC-CM. The recordings started with NCM as the bath solution; the horizontal bar indicates the period during which SC-CM was applied.

found that both SC-CM and NCM contained the same $\mathrm{K}^{+}$concentration, $4 \mathrm{~mm}$. In addition, when high $\mathrm{K}^{+}(16 \mathrm{~mm})$ saline was added to the bath solution, the holding current changed and the SSC frequency increased instantaneously (data not shown; also see Fig. $4 A$ ). In contrast, the resting potential of the myocyte was not altered by SC-CM, and the increase in the SSC frequency by SC-CM occurred gradually. Therefore, the increase in SSC fre- quency by SC-CM was not an artifact of high osmolarity, changes in $\mathrm{pH}$, or high $\mathrm{K}^{+}$concentration; it was most likely attributed to diffusible factors produced by Schwann cells.

To test whether the effect of increasing SSC frequency might be attributed to nonspecific factors released by cells under the culture condition, we collected conditioned medium from pure Xenopus fibroblast cultures. Neither the frequency nor the amplitude of SSCs was changed by fibroblast-conditioned medium (data not shown). Therefore, the potentiation of spontaneous synaptic activity is a specific property of Schwann cells.

The increase in SSC frequency by SC-CM is a presynaptic effect and is independent of neuronal action potentials

To distinguish the presynaptic from the postsynaptic mechanism of the synaptic potentiation, we compared the mean and distribution of SSC amplitudes before the SC-CM treatment with those after the treatment. Unlike the SSC frequency, the mean amplitude of SSCs remained unchanged after the SC-CM treatment (Fig. 2A). The mean amplitude of SSCs after the SC-CM treatment was $105 \pm 15 \%$ of that before it, which was not significantly different $(p>0.05)$. The distribution of SSC amplitudes was also not altered by SC-CM, as shown in the cumulative plot in Figure $2 B$. Therefore, the potentiation of SSC frequency by SC-CM was attributed to an increase in the presynaptic, spontaneous release rather than changes in the postsynaptic receptors.

To test whether SC-CM-induced presynaptic activity was mediated by enhancing the neuronal excitability, we recorded SSCs in the presence of tetrodotoxin (TTX) $(1 \mu \mathrm{M})$, which has been shown to block action potentials in Xenopus spinal neurons (Xie and Poo, 1986). The effectiveness of TTX in blocking neuronal action potentials in this preparation was confirmed as the evoked synaptic currents disappeared within $3 \mathrm{~min}$ after its application. However, the potentiation of spontaneous synaptic release by SC-CM was not blocked by TTX (Fig. 2C). We also recorded directly from the neuron soma and found that SC-CM did not trigger motoneurons to fire action potentials (data not shown). Using current-clamp recording, we did not find significant changes in the resting potential in neurons after the application of SC-CM. These results suggest that the increase in SSC frequency by SC-CM is not mediated by enhancing excitability in motoneurons.

\section{Schwann cell-conditioned medium effect requires $\mathrm{Ca}^{2+}$ influx}

To study the potential mechanisms of the SC-CM effect, we tested whether the massive increase in transmitter release by SC-CM might be attributed to an increase in $\mathrm{Ca}^{2+}$ influx. The intracellular $\mathrm{Ca}^{2+}$ concentration was monitored using ratiometric $\mathrm{Ca}^{2+}$ imaging technique after being stained with fura-2 AM. An example of $\mathrm{Ca}^{2+}$ imaging is shown in the top panel of Figure $3 A$; the neuronal cytoplasmic $\mathrm{Ca}^{2+}$ concentration was elevated to $\sim 150$ nM after 2 min in SC-CM. It appeared that, in some neurons, $\mathrm{Ca}^{2+}$ concentrations oscillated with variable amplitudes $(50-100 \mathrm{~nm})$ and frequencies $(0.015-0.02 \mathrm{~Hz})$, which may reflect cycles of voltage-dependent $\mathrm{Ca}^{2+}$ entry and/or internal uptake and release of $\mathrm{Ca}^{2+}$ (Friel, 1995). Because the increase in SSC frequency usually emerged 3-15 min after the application of SC$\mathrm{CM}$, the preceding elevation of cytoplasmic $\mathrm{Ca}^{2+}$ concentration may play an important role in triggering the downstream signaling pathways involved in SC-CM effect. The $\mathrm{Ca}^{2+}$ concentration in axons was monitored as well, and we found it increased in SC-CM at a similar time course as those in neuronal soma, suggesting that the rise of $\mathrm{Ca}^{2+}$ concentration in the axon might be 
A
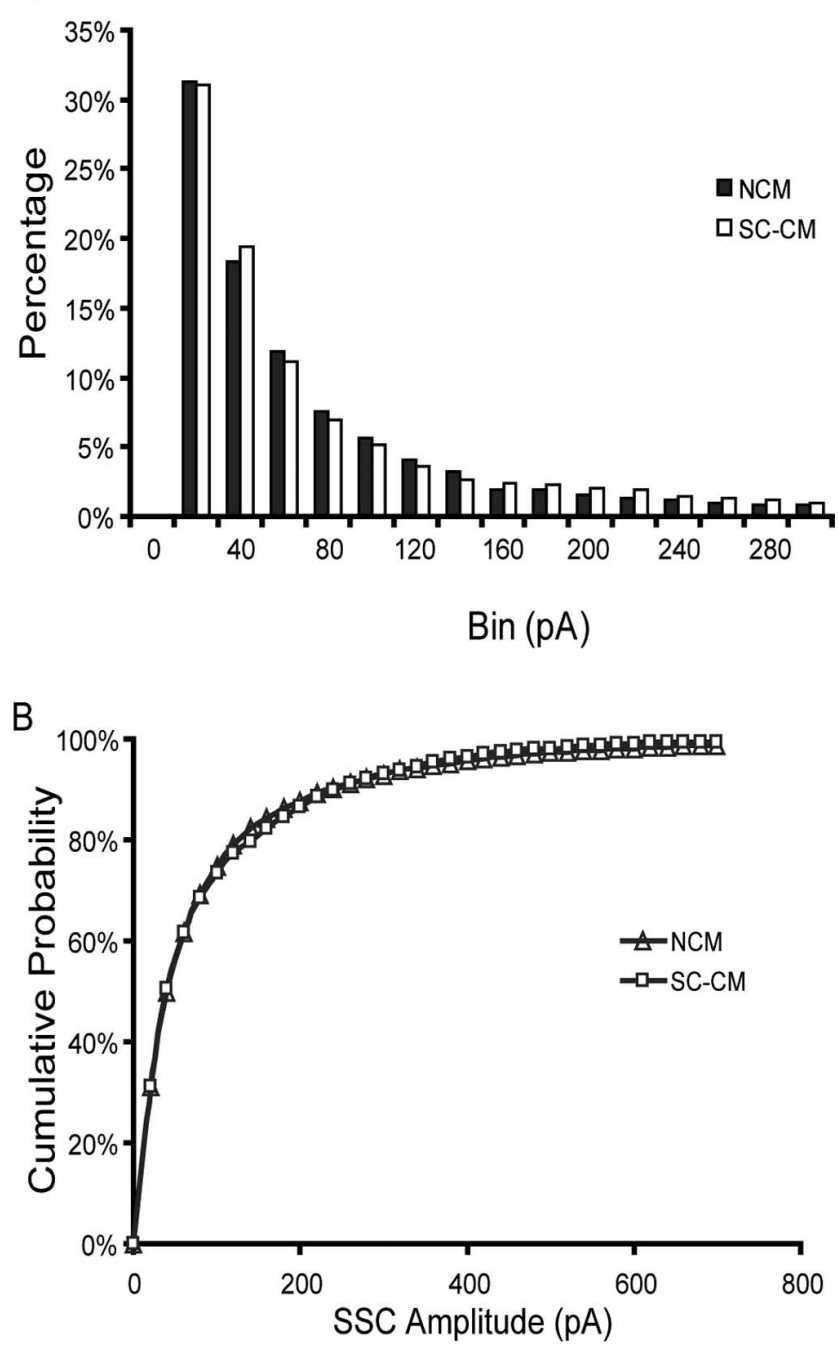

C

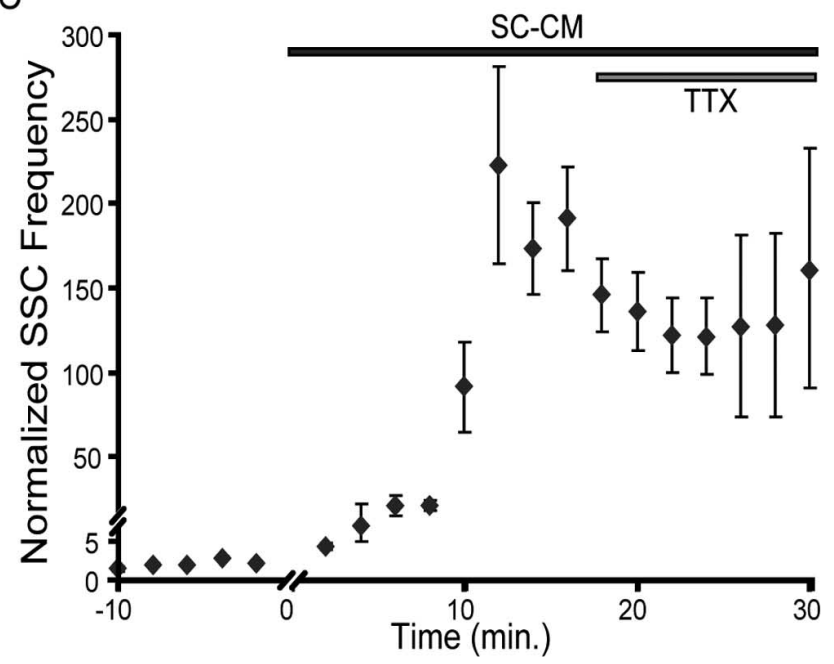

Figure 2. The potentiation of SSC frequency by SC-CM is a presynaptic effect and is independent of motoneuron action potentials. $A$, Histograms of amplitude distribution of SSCS recorded in NCM (filled bars) for 10 min immediately before and 20 min after SC-CM (open bars) treatment. The normalized events were averaged from eight myocytes. $\boldsymbol{B}$, The cumulative probability of the distributions of $\mathrm{SS}$ (amplitudes before (triangles) and after (squares) the treatment of SC-CM. The bin size is $20 \mathrm{pA}$. Cumulative probability refers to the probability of collecting events, whose amplitudes were equal or less than the given amplitude. The curve represents the aver- attributed to $\mathrm{Ca}^{2+}$ influx via axon surface $\mathrm{Ca}^{2+}$ channels instead of diffusion from the soma. In contrast, we did not see any changes in the intracellular $\mathrm{Ca}^{2+}$ level in myocytes by the SC-CM treatment (data not shown). These results suggest that SC-CM acts on soma and axons but not on myocytes.

To further confirm the involvement of $\mathrm{Ca}^{2+}$ influx in SC-CM effect, we tested the effect of $\mathrm{Ca}^{2+}$ blockers on the potentiation of spontaneous synaptic release triggered by SC-CM. As shown in Figure $3 B$, the increase in SSC frequency induced by SC-CM was totally abolished after the application of $\mathrm{Cd}^{2+}(0.2 \mathrm{mM})$, a nonspecific $\mathrm{Ca}^{2+}$ channel blocker (Brown and Dale, 2002), indicating that the $\mathrm{Ca}^{2+}$ influx was essential for the SC-CM effect. There are two major types of voltage-gated calcium channels in Xenopus motoneurons: N-type and L-type $\mathrm{Ca}^{2+}$ channels (Sand et al., 2001). To investigate which specific types of $\mathrm{Ca}^{2+}$ channels were involved in the SC-CM effect, we used CgTX (1 $\mu \mathrm{M})$ and nifedipine $(10 \mu \mathrm{M})$ to block $\mathrm{N}$-type and L-type $\mathrm{Ca}^{2+}$ channels, respectively. To avoid the variations of synaptic potentiation caused by different batches of SC-CM, the same batch of SC-CM was used for both control and drug-treated experiments throughout this work. As shown in Figure 3C, the average increase in SSC frequency by SC-CM reached $>100$-fold initially and $\sim 50$-fold of the control level at $20 \mathrm{~min}$ after SC-CM treatment in a group of four experiments. The application of CgTX inhibited the initial increase in SSC frequency induced by SC-CM; however, it did reach a similar level of increase in the presence of CgTX compared with the control group seen at $20 \mathrm{~min}$ in SC-CM. In the presence of nifedipine, the SSC frequency was still significantly increased $\sim 10$-fold at $20 \mathrm{~min}$ in SC-CM, but this increase was significantly reduced compared with SC-CM without the addition of nifedipine. Only the combination of CgTX and nifedipine totally blocked the increase in SSC frequency induced by SC-CM. These findings suggest that both $\mathrm{N}$-type and L-type $\mathrm{Ca}^{2+}$ channels were involved in the entry of $\mathrm{Ca}^{2+}$, but L-type $\mathrm{Ca}^{2+}$ channels mediated the majority of the $\mathrm{Ca}^{2+}$ influx. In contrast to the transmitter release induced by SC-CM, the spontaneous synaptic release in normal culture medium was not affected by the addition of CgTX, nifedipine, or both at the same concentrations (data not shown); the result is consistent with the previous report that normal spontaneous synaptic release at developing Xenopus NMJs does not require extracellular $\mathrm{Ca}^{2+}$ (Evers et al., 1989).

We also investigated whether the intracellular $\mathrm{Ca}^{2+}$ stores were involved in the SC-CM effect. Cultures were first incubated in NCM containing thapsigargin $(2 \mu \mathrm{M})$, an inhibitor of the $\mathrm{Ca}^{2+}$-ATPase pump of internal $\mathrm{Ca}^{2+}$ stores, to empty internal $\mathrm{Ca}^{2+}$ stores (Thastrup et al., 1990; Castonguay and Robitaille, 2001). Although thapsigargin could cause a transient increase in internal $\mathrm{Ca}^{2+}$, which elevates SSC frequency, the transient increase subsided before treatment with SC-CM containing thapsigargin. We found that SC-CM could still induce a drastic increase in SSC frequency in cultures treated with thapsigargin, albeit not as much as that without thapsigargin treatment (32fold vs 80 -fold at $20 \mathrm{~min}$ after treatments). Therefore, although internal $\mathrm{Ca}^{2+}$ stores may be partially involved, results shown in Figure $3 C$ suggest that the influx of extracellular $\mathrm{Ca}^{2+}$ through

age distribution of SSC amplitudes from eight NMJs. The distribution of SSC amplitudes after the application of SC-CM was not significantly different from that before the application of SC-CM ( $p>0.1$, Kolmogorov-Smirnov test). C, Summary data showing that the SC-CM effect is independent of neuronal action potentials $(n=4)$. TTX had no effect on the high-frequency spontaneous synaptic release induced by SC-CM. Each data point represents normalized mean \pm SEM SSC frequency. 

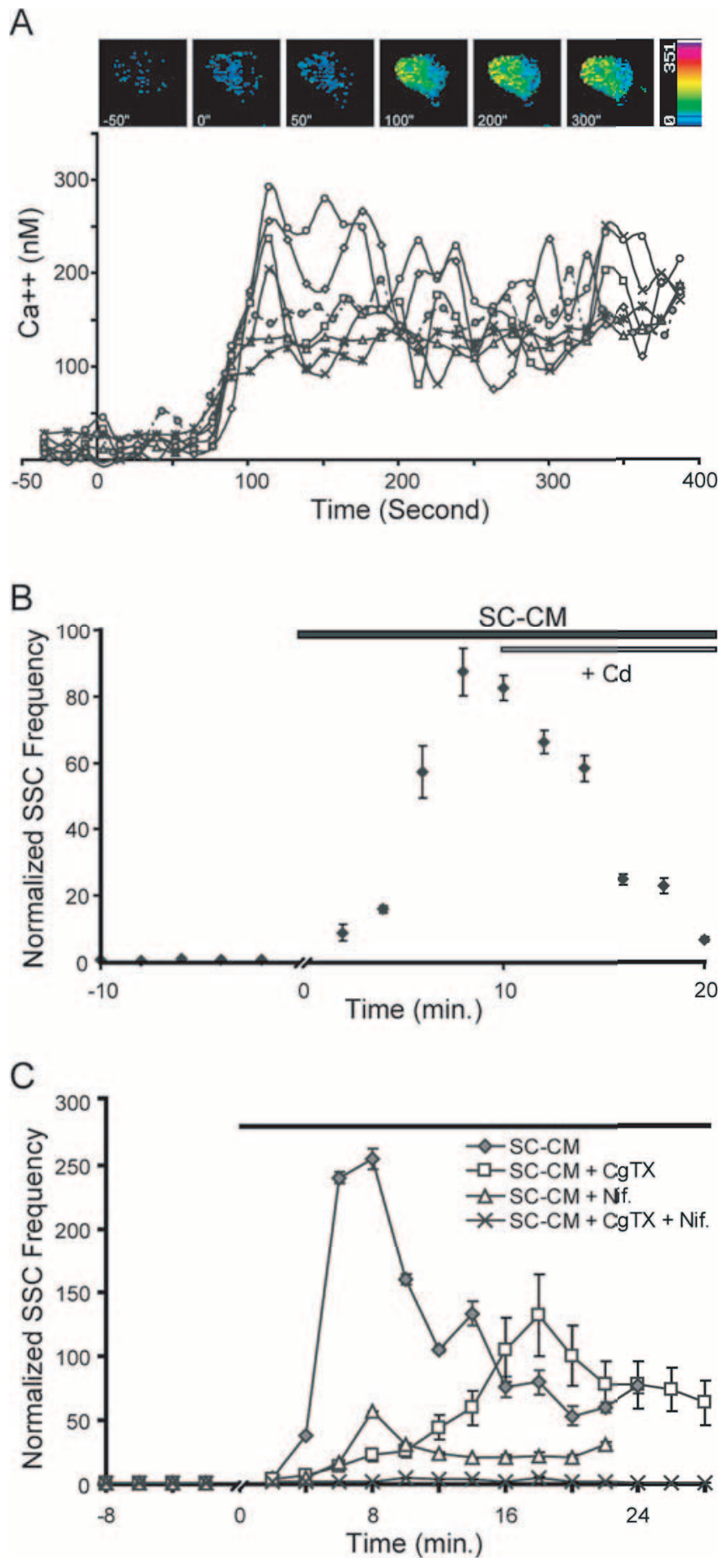

Figure 3. The $\mathrm{Ca}^{2+}$ involvement in the SC-CM effect. $\boldsymbol{A}$, The intracellular $\mathrm{Ca}^{2+}$ concentration in motoneuron soma was increased by $\mathrm{SC}-\mathrm{CM}$. Top, An example showing a series of $\mathrm{Ca}^{2+}$ images taken sequentially as the SC-CM was applied at the time of $0 \mathrm{~s}$. Bottom, Seven experiments showing the cytoplasmic $\mathrm{Ca}^{2+}$ concentration change inside the neuronal soma with time. The SC-CM was applied at $0 s$ in all experiments. B, Summary data for the change in SSC frequency after the application of $\mathrm{SC}-\mathrm{CM}$, followed by the addition of $\mathrm{Cd}^{2+}(0.2 \mathrm{~mm})(n=9)$. The application of SC-CM and $\mathrm{Cd}^{2+}(0.2 \mathrm{~mm})$ is marked by the black and gray horizontal bars, respectively. The increase in SSC frequency (mean \pm SEM) by SC-CM was completely suppressed after the blockade of extracellular $\mathrm{Ca}^{2+}$ influx by $\mathrm{Cd}^{2+}$. Each data point represents normalized mean \pm SEM SSC frequency. C, The SSC frequency changes induced by SC-CM in the presence of different types of $\mathrm{Ca}^{2+}$ channel blockers ( $n=4$ for each group of experiments). SC-CM was applied to neuromuscular synapses by itself (diamonds) or combined with $\mathrm{N}$-type $\mathrm{Ca}^{2+}$ channel blocker $\mathrm{CgTX}(1 \mu \mathrm{M})$ (squares), the L-type $\mathrm{Ca}^{2+}$ channel blocker nifedipine (10 $\mu \mathrm{M}$ ) (Nif; triangles), or both $(X)$. At 20 min after treatments, the average SSC frequencies in SC-CM alone, SC-CM plus CgTX, SC-CM plus nifedipine, and SC-CM plus CgTX plus nifedipine voltage-sensitive $\mathrm{N}$ - and L-type $\mathrm{Ca}^{2+}$ channels plays the major and essential role in the increase in transmitter release by SC-CM.

\section{Schwann cell-conditioned medium effect requires the motoneuron soma}

Because SC-CM increased the SSC frequency via presynaptic modulation of neurotransmitter secretion, it may act directly on the nerve terminal and/or other parts of the cell. We first tested whether the neuronal soma was required for the SC-CM function. The neuronal soma was removed by severing the axon near the soma with a sharp micropipette (Stoop and Poo, 1995). As shown in Figure $4 A$, the high-frequency spontaneous release induced by SC-CM was diminished sharply right after the removal of motoneuron soma. To exclude the possibility that the decrease in SSC frequency was an artifact of nerve terminal damage during the procedure of severing the axon, we applied a high concentration of $\mathrm{K}^{+}$saline to the bath and immediately observed massive neurotransmitter release, which indicated that the synapse was intact and further confirmed that the enhancement of synaptic release induced by SC-CM was not attributable to high $\mathrm{K}^{+}$. The effect of soma removal suggests that the continuous presence of signals from the motoneuron soma is indispensable for the potentiation of SSC frequency by SC-CM.

There were two possible signal pathways through which the motoneuron soma could have involved itself in the SC-CM effect. First, active factors in SC-CM that were bound directly to the soma could send signals to nerve terminals that increased the neurotransmitter release; second, active factors in SC-CM that were bound to receptors located on the nerve and its terminal could send signals to the soma via retrograde axonal transport, in which downstream signals were generated and sent back to the nerve terminal to increase spontaneous synaptic release. It is also possible that SC-CM acted on both the soma and the nerve. To investigate the functional sites of SC-CM, we used the focal application technique to apply SC-CM locally to either the motoneuron soma or the synaptic sites using a pair of perfusion micropipettes as described previously (Stoop and Poo, 1995). A vital dye, trypan blue, was added to the medium to visualize the flow and ensure that SC-CM was only focally applied to the soma or the synaptic sites. The frequency of SSCs increased dramatically up to 400-fold within 4-10 min after the focal application of $\mathrm{SC}-\mathrm{CM}$ to the motoneuron soma $(n=5)$ (Fig. $4 B$, diamonds). Although SSC frequency also increased when SC-CM was focally applied to the nerve-muscle contact $(n=4)$ (Fig. $4 B$, squares), the increase was rather modest, only up to approximately eightfold even at $20 \mathrm{~min}$ after application. The result suggests that the functional site of active factors in SC-CM was located primarily on the motoneuron soma. The relatively modest increase in SSC frequency by focal application on the nerve terminal region suggests that SC-CM may also act on axons and nerve terminals that require a longer period of SC-CM application for the slow retrograde transport effect to be observed (see Discussion).

Because the SC-CM effect lasted for as long as $2.5 \mathrm{~h}$ and continuously required signals from the motoneuron soma, we tested whether protein synthesis was required for the effect. The nervemuscle culture was pretreated with anisomycin $(30 \mu \mathrm{M})$, a pro-

$\leftarrow$

were 42.42-fold, 48.04-fold, 10.47-fold, and 1.18-fold of that in NCM, respectively. The SSC frequency (mean \pm SEM) in SC-CM is significantly higher than that in SC-CM plus nifedipine, which in turn is significantly higher than that in NCM ( $p<0.05, t$ test). The horizontal bar indicates the period during which SC-CM with or without $\mathrm{Ca}^{2+}$ channel blockers was applied. Each data point represents normalized mean \pm SEM SSC frequency. 
A

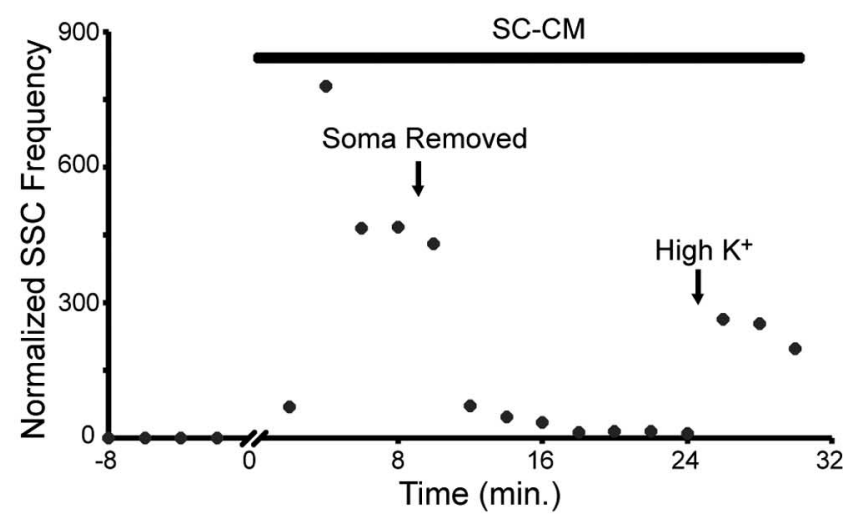

B

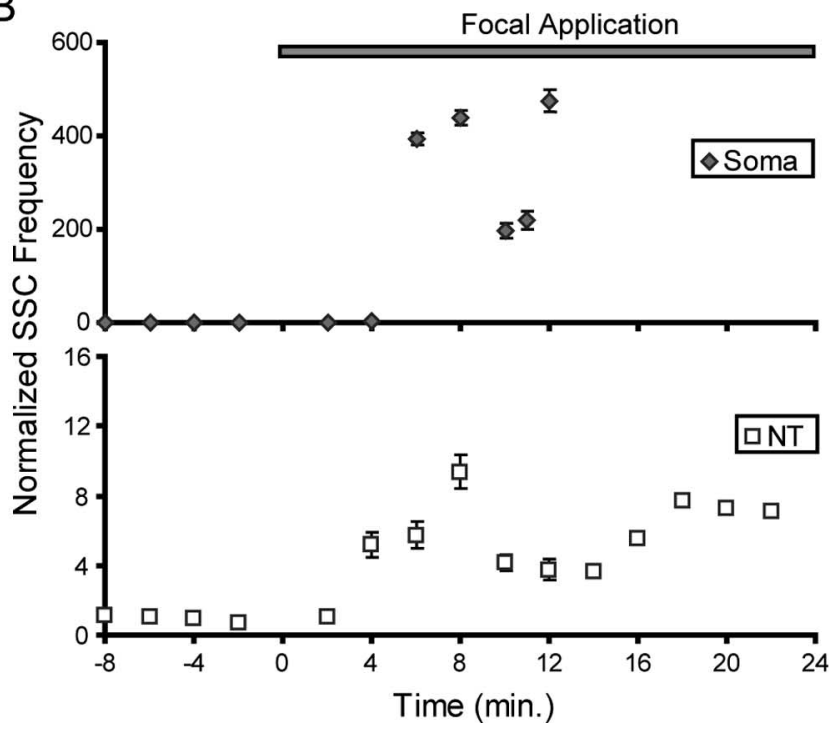

Figure 4. The increase in SSC frequency by SC-CM requires the signal from the soma. $A, A n$ example showed that the potentiation of spontaneous synaptic release by SC-CM was blocked after the motoneuron soma was removed. In contrast, high $\mathrm{K}^{+}$increased the SSC frequency despite the removal of the motoneuron soma, which confirmed the vitality of the synapse. The duration of SC-CM application is marked with the horizontal bar. The removal of the motoneuron soma and the addition of high concentration of $\mathrm{K}^{+}$are marked by arrows. $\boldsymbol{B}$, Focal application of SC-CM with a pair of electrode pipettes. SC-CM, mixed with trypan blue as an indicator for the flow, was locally applied by perfusion toward the motoneuron soma (diamonds; $n=5$ ) or the nerve-muscle contact (squares; $n=4)$. When SC-CM was focally applied to the soma, the SSC frequency greatly potentiated, up to 400 -fold. In contrast, only an approximately eightfold increase was seen when SC-CM focally applied to the nerve terminal region (NT). The SSC frequency was normalized with the average SSC frequency before the SC-CM application. Each data point represents normalized mean \pm SEM SSC frequency.

tein synthesis inhibitor, for $45 \mathrm{~min}$, and we found that SC-CM still enhanced the spontaneous synaptic release $(n=4)$. The effectiveness of anisomycin was confirmed by blocking cerebellar long-term depression, which has been shown to require protein synthesis (McEvoy et al., 2007). Zhang and Poo (2002) reported that brain-derived neurotrophic factor (BDNF) required local protein synthesis to potentiate synaptic release, which was blocked by inhibiting protein synthesis for a prolonged period ( 2 h) instead of short-term treatment ( $45 \mathrm{~min})$. To exclude the possibility that there were still enough residual products remaining in the cell body to carry on SC-CM effect after a short-term period (45 min) of anisomycin treatment, we pretreated the nerve-muscle culture for $2 \mathrm{~h}$; the potentiation effect of SC-CM still remained unaffected $(n=3)$. These findings suggest that the $\mathrm{SC}-\mathrm{CM}$ effect does not require protein synthesis.

\section{The potentiation effect of SC-CM may be attributed to novel factors released by Schwann cells}

Schwann cells release a variety of molecules, including neurotrophins and growth factors (Scherer and Salzer, 1996; Mirsky and Jessen, 1999). To investigate the identity of active factors in SC-CM that increased the SSC frequency, we first determined the range of the molecular weights of active factors in SC-CM using several molecular weight cutoff centrifugal filters. These filters separate different components by only allowing molecules with less than the cutoff molecular weight of the filter through. We found that, after filtration with 10 or $5 \mathrm{kDa}$ cutoff filters, SC-CM still had the same effect as unfiltered conditioned medium. This suggests that the active factors in SC-CM are small molecules of $<5 \mathrm{kDa}$. We further dialyzed SC-CM with a $500 \mathrm{Da}$ cutoff dialysis membrane, which removed all molecules with molecular weights below $500 \mathrm{Da}$. The dialyzed SC-CM showed a similar effect in increasing SSC frequency as the one before dialysis. Therefore, the molecular weight of active factors in SC-CM is most likely in the range of 500-5000 Da.

We then tested several factors that have been shown previously to enhance transmitter release. For example, ATP, a small molecule (molecular weight, 551.1) that can be released by cultured Schwann cells (Liu and Bennett, 2003), has been demonstrated to modulate synaptic transmission and mediate the neuron-glia interactions (Fu and Poo, 1991; Fields and Stevens, 2000). Previous reports have shown that ATP binds to the purinergic $\mathrm{P} 2$ receptor on muscles. ATP then activates the protein kinase $\mathrm{C}(\mathrm{PKC})$ signal pathway, which can be inhibited by the $\mathrm{P} 2$ receptor blocker reactive blue $2(10 \mu \mathrm{M})$ or the PKC inhibitor staurosporine $(0.5 \mu \mathrm{M})$ (Fu et al., 1997). To test whether the SC-CM effect was mediated by ATP, we applied RB2 or staurosporine to SC-CM and found that neither reactive blue 2 nor staurosporine could block the SC-CM-induced increase in SSC frequency ( $n=4$ for each group). As shown in Figure $5 A$, staurosporine blocked the SSC frequency increase induced by ATP (a) but not by SC-CM (b). Because the increase in SSC frequency by $\mathrm{SC}-\mathrm{CM}$ requires the presence of neuronal soma, we applied ATP (0.3 mM) after the removal of motoneuron soma. As shown in Figure 5B, SC-CM could not increase SSC frequency after the soma removal; in contrast, ATP potentiated the spontaneous synaptic release even without the motoneuron soma. We also tested whether adenosine was involved in the SC-CM effect and found that adenosine did not increase the SSC frequency, and the adenosine receptor antagonist 8-(sulfophenyl)-theophylline (0.1 $\mathrm{mM}$ ) did not block the potentiation of SSC frequency by SC-CM ( $n=4$; data not shown). Therefore, the SC-CM effect is not likely attributed to ATP or its derivatives.

The potential involvement of another small molecule that modulates synaptic transmission, glutamate, was also assayed in our system. Fu et al. (1995) found that glutamate could reversibly potentiate spontaneous synaptic release at developing NMJs, and the major functional sites of glutamate were located in synaptic regions. We confirmed that the SSC frequency increased dramatically when glutamate was focally applied to the nerve-muscle contact region. However, we found that focal application of SC-CM to the nerve-muscle contacts had only a modest effect on SSC frequency (Fig. 4B). Although the SC-CM effect requires the presence of soma, the synaptic potentiation by glutamate does not. Furthermore, as mentioned previously, SC-CM was still potent in increasing the SSC frequency after dialyzed with a $500 \mathrm{Da}$ 


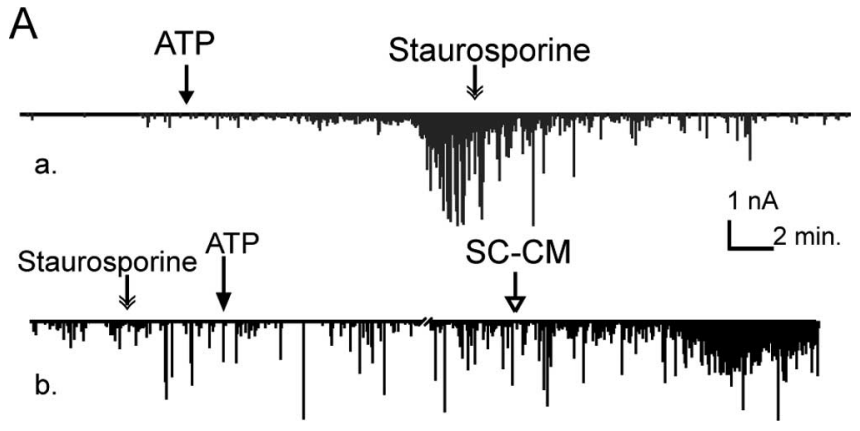

$\mathrm{B}$

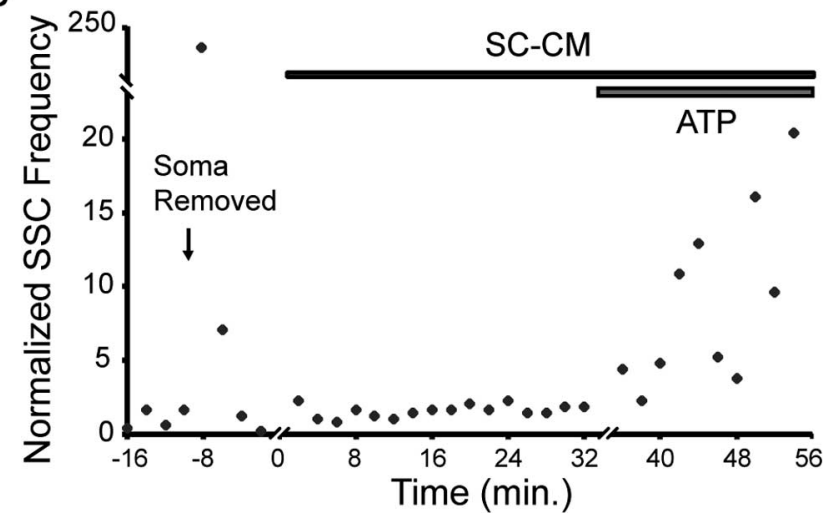

Figure 5. The SC-CM effect is not mediated by ATP. $A$, The SC-CM effect has different signal pathways from ATP. $\boldsymbol{a}$, ATP $(0.3 \mathrm{~mm})$ increased the SSC frequency, which was blocked by a PKC inhibitor, staurosporine $(0.5 \mu \mathrm{m}) . \boldsymbol{b}$, With the addition of staurosporine in the bath, ATP could not increase the SSC frequency, but SC-CM did. The line breaker (//) marks a 20 min interval. $\boldsymbol{B}$, The potentiation of spontaneous synaptic release by ATP does not require the motoneuron soma. The removal of motoneuron soma is indicated by an arrow, the application of SC-CM is marked by a solid horizontal bar, and the addition of ATP is represented by a gray horizontal bar. Right after the soma removal, the SSC frequency increased instantly to $>200$-fold of the control level attributable to the massive influx of bath $\mathrm{Ca}^{2+}$ into the axon from the trunk opening, as shown previously by Stoop and Poo (1995). After the removal of excessive internal $\mathrm{Ca}^{2+}$ at the nerve terminal, the SSC frequency returned to the control level, and the application of SC-CM could not increase SSC frequency. However, ATP could still increase the frequency of spontaneous release after the motoneuron soma was removed.

cutoff dialysis membrane, which should have completely removed any possible glutamate molecules from the solution, because the molecular weight of glutamate is $169.1 \mathrm{Da}$. The effectiveness of the dialysis method was confirmed because we found that the solution with a high concentration of glutamate $(20 \mathrm{~mm})$, which could increase the SSC frequency dramatically, had no effect on SSC frequency when applied to NMJs after dialysis with a $500 \mathrm{Da}$ cutoff dialysis membrane. Thus, the SC-CM effect is not likely to be mediated by glutamate.

It has been well documented that neurotrophins, including BDNF, ciliary neurotrophic factor (CNTF), and neurotrophin-3 (NT-3), can acutely potentiate transmitter release at the Xenopus nerve-muscle culture (Poo, 2001). However, these neurotrophins are proteins with molecular weights $>10 \mathrm{kDa}$. Furthermore, BDNF was able to increase SSC frequency after removing the motoneuron soma, whereas the $\mathrm{SC}-\mathrm{CM}$ effect required the motoneuron soma. Similar to SC-CM, CNTF and NT-3 require the motoneuron soma for their potentiation effect in the SSC frequency; however, the increase in SSC frequency induced by CNTF and NT-3 does not require $\mathrm{Ca}^{2+}$ influx (Stoop and Poo, 1996; He et al., 2000). Therefore, the SC-CM effect is unlikely mediated by these neurotrophins either.
Schwann cells were reported to produce prostaglandins (Constable et al., 1994; Muja and DeVries, 2004), which have small molecular weights and can modulate synaptic transmission (Harish and Poo, 1992). In our preparation, PGE2 (50 $\mu \mathrm{M})$ increased the SSC frequency by 50 - to 100 -fold ( $n=4$; data not shown), and this enhancement of spontaneous release was blocked by the addition of EP1 prostanoid receptor antagonist SC-19220 (30 $\mu \mathrm{M})$ (Kennedy et al., 1982; Fujita et al., 1992). However, we found that the SC-CM effect was not affected by SC-19220 $(n=5)$. It has been shown that glia also produce cholesterol and TNF- $\alpha$, which can modulate synaptic efficacy in synapses in the CNS (Murwani et al., 1996; Mauch et al., 2001; Beattie et al., 2002). However, we found that treatments with cholesterol $(10 \mu \mathrm{g} / \mathrm{ml})$ or TNF- $\alpha$ (6 nM) had no acute effect on spontaneous synaptic release at Xenopus nerve-muscle culture even after being applied for $1 \mathrm{~h}(n=4$ for each molecule). Thus, $\mathrm{SC}-\mathrm{CM}$ potentiation is not likely mediated by prostaglandins, cholesterol, or TNF- $\alpha$.

The comparison between SC-CM and some of those known factors that acutely modulate synaptic transmission at developing NMJs is listed in Table 1. Based on the above studies, we conclude that the SC-CM effect is not attributed to any of those known factors discussed above. Schwann cells may release some novel factors that enhance spontaneous synaptic release at developing neuromuscular synapses. Because the potentiation effect is greatly reduced by SC-CM after heat denature $(9.6 \pm 1.3$-fold in heat-denatured SC-CM vs $253.7 \pm 68.3$-fold in control SC-CM), the novel factors are likely peptides in nature (supplemental data, available at www.jneurosci.org as supplemental material). The identity of active factors in SC-CM remains to be investigated.

\section{SC-CM inhibits evoked synaptic activities}

Because SC-CM increased the frequency of spontaneous transmitter release, we tested further whether the evoked synaptic release was also modulated by SC-CM. The motoneurons were loosely patched on the soma with a micropipette as a stimulation electrode. Suprathreshold stimuli were given at a frequency of $0.05 \mathrm{~Hz}$. In contrast to the potentiation of spontaneous synaptic release, SC-CM gradually suppressed the amplitude of the ESCs until ESCs were totally extinguished within $10 \mathrm{~min}$ (Fig. 6). The suppression of ESC amplitude by SC-CM was reversible, because the evoked synaptic responses recovered after the SC-CM was replaced with normal culture medium. The inhibition of ESCs was accompanied by high-frequency spontaneous synaptic release caused by SC-CM. It is worthy to mention that BDNF, CNTF, and NT-3 all increased ESC amplitude, which further suggests that the SC-CM effect is not attributed to these neurotrophins.

\section{SC-CM potentiates spontaneous synaptic release at developing NMJs in situ}

To test whether Schwann cell-derived factors had similar modulatory effects in vivo, we examined the SC-CM effect on developing NMJs in the frog (Xenopus laevis) tadpole (stage 60-63). The osmolarity of SC-CM and NCM was adjusted from 280 to 230 $\mathrm{mmol} / \mathrm{kg}$, the same level in the normal frog Ringer's solution, by adding deionized water accordingly. mEPPs were recorded with intracellular electrodes from the pectoral muscle in situ without removing the muscle from the anesthetized tadpole. Because the pectoral muscle in stage $60-63$ is very small and thin, the intracellular recording from each muscle fiber usually can only last for 2-3 min. We randomly selected muscle fibers and recorded from each muscle fiber for $1 \mathrm{~min}$. The population of $\mathrm{mEPP}$ frequencies 
The comparison between SC-CM and known factors that modulate synaptic activities

\begin{tabular}{|c|c|c|c|c|c|}
\hline & Extracellular calcium influx & Require neuron soma & Neuron cytosolic Ca & Presynaptic or postsynaptic effect & Molecular weight \\
\hline BDNF & + & - & $\uparrow$ & Pre & $12.3 \mathrm{kDa}$ \\
\hline NT-3 & - & + & $\uparrow$ & Pre & $13.6 \mathrm{kDa}$ \\
\hline CNTF & - & + & NC & Pre & $22.8 \mathrm{kDa}$ \\
\hline ATP & + & - & NA & Post & 551.1 \\
\hline Glutamate & + & - & $\uparrow$ & Pre & 147.1 \\
\hline SC-CM & + & + & $\uparrow$ & Pre & $500-5000 \mathrm{Da}$ \\
\hline
\end{tabular}

NC, No changes; NA, not available.

A

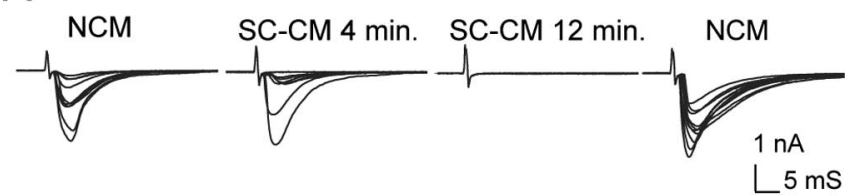

B

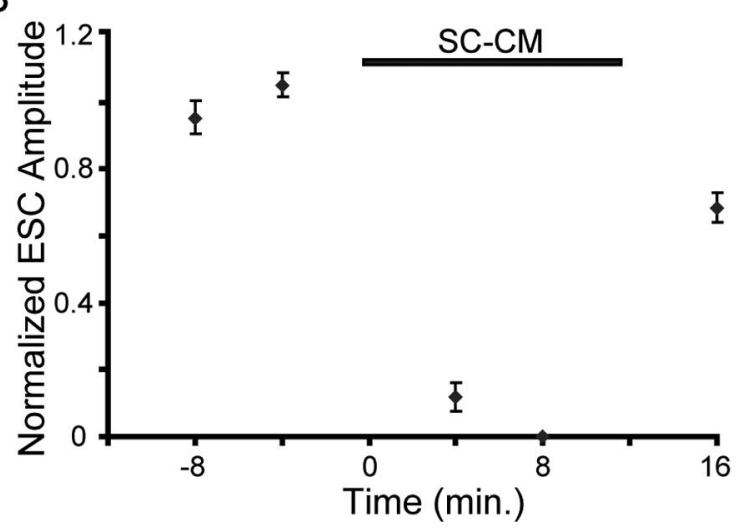

Figure 6. SC-CM reversibly inhibits evoked synaptic transmission. $\boldsymbol{A}$, An example showing that SC-CM inhibits ESCS. The motoneuron was stimulated at the soma with an extracellular microelectrode at the frequency of $0.05 \mathrm{~Hz}$. Samples of ESCs were recorded at different times when the neuromuscular synapse was in NCM, then SC-CM, and then NCM again. $B$, Summary of the changes of mean ESC amplitudes in SC-CM $(n=4)$. All ESC amplitudes were normalized with the mean ESC amplitude before SC-CM treatment. The horizontal bar indicates the period when SC-CM was applied. Each data point represents normalized mean \pm SEM ESC amplitude.

in NCM was compared with that in SC-CM (Fig. 7). The average mEPP frequency increased $\sim 2-, 17$-, and 15-fold after the muscle was in SC-CM for 1, 2, and $3 \mathrm{~h}$, respectively. This result suggests that Schwann cell-derived factors can potentiate spontaneous synaptic activities at developing NMJs in vivo. Whether SC-CM also contributes to synaptic potentiation at adult NMJs is situ remains to be investigated.

\section{Discussion}

In the present study, we have shown that Schwann cells release factors that acutely and massively enhance spontaneous transmitter release, whereas they inhibit evoked synaptic currents at developing neuromuscular junctions in Xenopus tissue culture. The SC-CM-induced potentiation, which requires the influx of $\mathrm{Ca}^{2+}$ through voltage-sensitive $\mathrm{Ca}^{2+}$ channels, is under immediate somatic control but does not depend on protein synthesis. The potentiation effect of SC-CM is mediated by small molecules, likely heat-sensitive peptides, with molecular weights within 500-5000 Da but not by ATP, glutamate, or any currently known neurotrophins. SC-CM can also enhance spontaneous mEPPs at developing NMJs in tadpoles. We propose that active factors released by perisynaptic Schwann cells are endocytosed and trans-

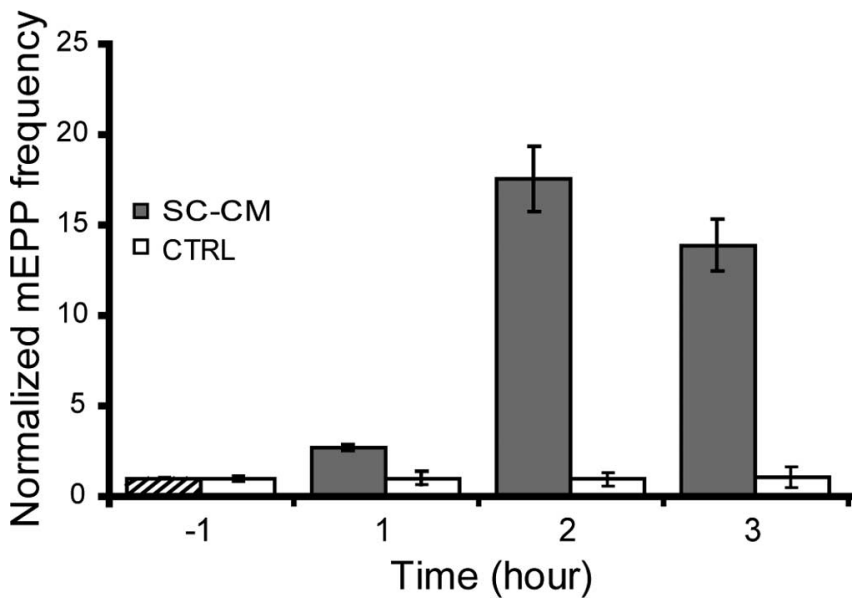

Figure 7. SC-CM enhances the frequency of $m$ EPPs at developing neuromuscular synapses in tadpoles. Intracellular recordings were made on randomly selected pectoral muscle fibers in tadpoles (stage $60-63$ ). The average mEPP frequency increased $\sim 2-, 17-$, and 15 -fold after the muscle was in SC-CM for 1, 2, and $3 \mathrm{~h}$, respectively. Each bar represents an average mEPP frequency recorded from $6-12$ muscle fibers in SC-CM (gray bar; $n=5$ tadpoles) and that in $\mathrm{NCM}$ (white bar; $n=3$ tadpoles). The first hatched bar represents average mEPP frequency in NCM before the application of SC-CM in the experimental group. For each individual experiment, the $m E P P$ frequency was normalized with the average $\mathrm{MEPP}$ frequency in NCM. Each bar represents the mean \pm SEM normalized mEPP frequency. CTRL, Control.

ferred to the motor neuron soma via slow, retrograde axon transport at developing NMJs. At the motoneuron soma, active factors bind to intracellular receptors and activate signal pathways that lead to the influx of $\mathrm{Ca}^{2+}$ in the soma, which triggers downstream pathways that result in enhanced spontaneous synaptic release. The increase in spontaneous neurotransmission induced by glial cells may promote synapse formation and stability.

\section{Schwann cells release soluble factors that acutely modulate} synaptic efficacy at developing NMJs

Using the criteria of molecular weights, somatic influence, and external $\mathrm{Ca}^{2+}$ dependency, as summarized in Table 1, we could exclude some Schwann cell-derived molecules, such as ATP, glutamate, prostaglandin, BDNF, NT-3, and CNTF, as the mediators for SC-CM-induced synaptic potentiation. Although SC-CM may also contain these molecules, the concentration may be too low to modulate synaptic release. We have recently found that SC-CM also contains transforming growth factor $\beta$-1 (TGF- $\beta 1$ ), which increases the number of nerve-muscle contacts in Xenopus tissue culture (Z. Feng and C. P. Ko, unpublished observations). However, TGF- $\beta 1$ itself does not induce an acute increase in transmitter release in culture. We also excluded other glialderived factors, such as cholesterol and TNF- $\alpha$, which have been shown to enhance synaptic efficacy in the CNS (Mauch et al., 2001; Beattie et al., 2002). A recent study has shown that thrombospondins released by astrocytes can also enhance synaptic function and formation in the CNS (Christopherson et al., 2005). 
However, thrombospondins are large molecules with molecular weights over $150 \mathrm{kDa}$ and thus are not likely candidates in mediating the potentiation effect induced by the small molecules (within 500 and $5000 \mathrm{Da}$ ) found in SC-CM.

Together, we can exclude most, if not all, of the known factors that have been shown to increase synaptic activities in the CNS and in the PNS from the candidates of active factors in frog SCCM. It is interesting to note that mammalian Schwann cells or derived factors can promote synapse formation and enhance synaptic function between retinal ganglion cells as well as between spinal motoneurons in culture (Ullian et al., 2004). Schwann cells can also promote the formation of NMJs between rat spinal motoneurons and human muscle fibers in culture (Guettier-Sigrist et al., 2000; Mars et al., 2001). However, the identity of mammalian Schwann cell-derived factors in these studies is not known. It would be important to identify active factors released by Schwann cells in mammals and other species to better understand the molecular basis of synapse-glia interactions.

\section{SC-CM has different effects on evoked versus spontaneous synaptic release}

The opposite effect on evoked versus spontaneous transmitter release by SC-CM has also been observed by ATP treatment in Xenopus nerve-muscle culture (Fu and Poo, 1991). This may reflect the property of developing synapses because the dependency on extracellular $\mathrm{Ca}^{2+}$ and the releasable vesicle pool for evoked and spontaneous synaptic transmission are different during the early development of Xenopus neuromuscular synapses (Evers et al., 1989). Furthermore, the elevated cytoplasmic $\mathrm{Ca}^{2+}$ concentration induced by SC-CM may diffuse from the soma to the nerve terminal and increase the $\mathrm{Ca}^{2+}$ concentration in the nerve terminal, which in turn can cause the $\mathrm{Ca}^{2+}$-dependent $\mathrm{Ca}^{2+}$ channel inactivation (Jones et al., 1999). In addition, the potentiated spontaneous synaptic release can enhance the depolarization of the nerve terminal via autoreceptors located on the nerve terminal (Fu et al., 1998). The depolarization of nerve terminals may induce voltage-dependent inactivation of voltagegated $\mathrm{Ca}^{2+}$ channels (Jones et al., 1999). Either $\mathrm{Ca}^{2+}$-dependent or voltage-dependent $\mathrm{Ca}^{2+}$ channel inactivation can lead to the suppression of transient $\mathrm{Ca}^{2+}$ influx at the active zone and thereby block the evoked synaptic release as suggested by Fu and Poo (1991). Also, it is notable that the suppression of evoked synaptic release is unlikely to be attributable to the depletion of releasable vesicle pool, because motoneurons can maintain highfrequency spontaneous release for at least $2 \mathrm{~h}$, whereas evoked synaptic currents are completely abolished.

\section{The potential mechanisms of the SC-CM effect}

Our results indicate that the increase in spontaneous transmitter release induced by SC-CM requires $\mathrm{Ca}^{2+}$ influx through voltagegated $\mathrm{Ca}^{2+}$ channels but does not depend on action potentials. Given the relatively slow time course in initiating the $\mathrm{Ca}^{2+}$ influx ( $2 \mathrm{~min}$ ) and synaptic potentiation effect (3-15 $\mathrm{min}$ ), as well as the independence of action potentials, it is unlikely that SC-CM activates voltage-gated $\mathrm{Ca}^{2+}$ channels directly. Alternatively, SC-CM may activate plasma membrane $\mathrm{Ca}^{2+}$ channels indirectly through intracellular signaling pathways, as shown in ligandgated $\mathrm{Ca}^{2+}$ channels in lymphocytes (Kuno and Gardner, 1987). Whether and how SC-CM activates voltage-gated $\mathrm{Ca}^{2+}$ channels through intracellular mediators remains to be investigated.

Our results also indicate that the potentiation of spontaneous transmitter release by SC-CM requires the motoneuron soma, but it does not require the short-term protein synthesis. Thus, the synaptic potentiation is likely under an immediate somatic control, as seen in CNTF-induced synaptic potentiation (Stoop and Poo, 1995). In addition to dispense the influx of $\mathrm{Ca}^{2+}$, the soma may also provide the continuous flow of synaptic vesicles to sustain the high-frequency spontaneous transmitter release seen in SC-CM. The focal application studies also suggest that SC-CM can act on not only the soma but also the nerve terminal. However, the focal application of SC-CM on the nerve-muscle contact elicits only an approximately eightfold increase in the spontaneous transmitter release even at $20 \mathrm{~min}$ after focal application compared with an $\sim 400$-fold increase by focal application on the soma. Because of the technical difficulty in continuous delivery of enough SC-CM from the pipette for $>30 \mathrm{~min}$, we could not exclude the possibility that longer treatment of SC-CM at the synaptic site may lead to a higher level of potentiation. It is possible that active factors in SC-CM can bind unknown receptors on the nerve terminal and be transported to the motoneuron soma via retrograde axonal transport and then potentiate spontaneous synaptic activities. Assuming that the signal at the nerve terminal is transferred to the soma, typically $100 \mu \mathrm{m}$ away, via the slow retrograde axonal transport (Brown, 2000), it would take $\sim 40-400$ min for the signal to reach the soma. Considering the amount of time for the soma to collect enough signals from the nerve terminal via slow axonal transport, it may take hours before the functional effect is eventually exhibited. Consistent with this idea is our finding that it took $\sim 1-2 \mathrm{~h}$ for SC-CM to enhance the spontaneous mEPP frequency at developing NMJs in Xenopus tadpole pectoral muscle in situ. Thus, SC-CM can potentiate spontaneous neurotransmission both in vitro and in vivo, which may play a role in the development of NMJs as discussed below.

\section{The possible role of enhanced spontaneous neurotransmission by Schwann cells in the development of NMJs}

It has been suggested that spontaneous acetylcholine release may have a trophic influence in synapse maturation in Xenopus nervemuscle culture (Fu and Poo, 1991). Many of the spontaneous synaptic potentials at developing NMJs are suprathreshold and can elicit muscle contraction (Xie and Poo, 1986), as also seen in our cultures treated with SC-CM. The suprathreshold excitation may produce global influence in the maturation of muscle fibers (Kidokoro and Saito, 1988) as well as acetylcholine receptor distribution during synaptogenesis (Kummer et al., 2006). Furthermore, synaptic activity plays a crucial role in the transition from multiple innervation to single innervation at developing neuromuscular synapses (Wyatt and Balice-Gordon, 2003). In addition to the global effects exerted by suprathreshold spontaneous synaptic activities, recent studies suggest that spontaneous miniature synaptic transmission, independent of evoked transmitter release, may regulate local postsynaptic protein synthesis and stabilize the structure and function of developing synapses (McKinney et al., 1999; Saitoe et al., 2001; Chung and Kavalali, 2006; Sutton et al., 2006). Our previous study using PSC ablation has shown that PSCs are essential for the growth and maintenance of developing NMJs in vivo (Reddy et al., 2003). Although the mechanisms are not known, it is tempting to speculate that the potentiation of spontaneous neurotransmission by Schwann cellderived factors may participate in the growth and maintenance of developing NMJs. The glial cell-induced synaptic enhancement, as also demonstrated in the central synapses, may be a common feature at developing synapses to promote synaptic maturation and stability in both CNS and PNS. 


\section{References}

Allen NJ, Barres BA (2005) Signaling between glia and neurons: focus on synaptic plasticity. Curr Opin Neurobiol 15:542-548.

Araque A, Parpura V, Sanzgiri RP, Haydon PG (1999) Tripartite synapses: glia, the unacknowledged partner. Trends Neurosci 22:208-215.

Astrow SH, Qiang H, Ko CP (1998) Perisynaptic Schwann cells at neuromuscular junctions revealed by a novel monoclonal antibody. J Neurocytol 27:667-681.

Auld DS, Robitaille R (2003) Perisynaptic Schwann cells at the neuromuscular junction: nerve- and activity-dependent contributions to synaptic efficacy, plasticity, and reinnervation. The Neuroscientist 9:144-157.

Beattie EC, Stellwagen D, Morishita W, Bresnahan JC, Ha BK, Von Zastrow M, Beattie MS, Malenka RC (2002) Control of synaptic strength by glial TNFalpha. Science 295:2282-2285.

Brown A (2000) Slow axonal transport: stop and go traffic in the axon. Nat Rev Mol Cell Biol 1:153-156.

Brown P, Dale N (2002) Spike-independent release of ATP from Xenopus spinal neurons evoked by activation of glutamate receptors. J Physiol (Lond) 540:851-860.

Castonguay A, Robitaille R (2001) Differential regulation of transmitter release by presynaptic and glial $\mathrm{Ca}^{2+}$ internal stores at the neuromuscular synapse. J Neurosci 21:1911-1922.

Christopherson KS, Ullian EM, Stokes CC, Mullowney CE, Hell JW, Agah A, Lawler J, Mosher DF, Bornstein P, Barres BA (2005) Thrombospondins are astrocyte-secreted proteins that promote CNS synaptogenesis. Cell 120:421-433.

Chung C, Kavalali ET (2006) Seeking a function for spontaneous neurotransmission. Nat Neurosci 9:989-990.

Constable AL, Armati PJ, Toyka KV, Hartung HP (1994) Production of prostanoids by Lewis rat Schwann cells in vitro. Brain Res 635:75-80.

Evers J, Laser M, Sun YA, Xie ZP, Poo MM (1989) Studies of nerve-muscle interactions in Xenopus cell culture: analysis of early synaptic currents. J Neurosci 9:1523-1539.

Feng Z, Ko CP (2007) Neuronal glia interactions at the vertebrate neuromuscular junction. Curr Opin Pharmacol 7:316-324.

Feng Z, Koirala S, Ko CP (2005) Synapse-glia interactions at the vertebrate neuromuscular junction. The Neuroscientist 11:503-513.

Fields RD, Stevens B (2000) ATP: an extracellular signaling molecule between neurons and glia. Trends Neurosci 23:625-633.

Fields RD, Stevens-Graham B (2002) New insights into neuron-glia communication. Science 298:556-562.

Friel DD (1995) Calcium oscillations in neurons. Ciba Found Symp 188: 210-223; discussion 223-234.

Fu WM, Poo MM (1991) ATP potentiates spontaneous transmitter release at developing neuromuscular synapses. Neuron 6:837-843.

Fu WM, Liou JC, Lee YH, Liou HC (1995) Potentiation of neurotransmitter release by activation of presynaptic glutamate receptors at developing neuromuscular synapses of Xenopus. J Physiol (Lond) 489:813-823.

Fu WM, Chen YH, Lee KF, Liou JC (1997) Regulation of quantal transmitter secretion by ATP and protein kinases at developing neuromuscular synapses. Eur J Neurosci 9:676-685.

Fu WM, Liou HC, Chen YH (1998) Nerve terminal currents induced by autoreception of acetylcholine release. J Neurosci 18:9954-9961.

Fujita A, Takeuchi T, Hata F, Yagasaki O (1992) Role of PGE2 in neurotransmission from pre- to post-ganglionic hypogastric nerves of guinea pigs. Jpn J Pharmacol 58:61-66.

Georgiou J, Robitaille R, Trimble WS, Charlton MP (1994) Synaptic regulation of glial protein expression in vivo. Neuron 12:443-455.

Guettier-Sigrist S, Coupin G, Warter JM, Poindron P (2000) Cell types required to efficiently innervate human muscle cells in vitro. Exp Cell Res 259:204-212.

Hamill OP, Marty A, Neher E, Sakmann B, Sigworth FJ (1981) Improved patch-clamp techniques for high-resolution current recording from cells and cell-free membrane patches. Pflügers Arch 391:85-100.

Harish OE, Poo MM (1992) Retrograde modulation at developing neuromuscular synapses: involvement of $\mathrm{G}$ protein and arachidonic acid cascade. Neuron 9:1201-1209.

Hatton GI, Parpura V (2004) Glial neuronal signaling. Boston: Kluwer Academic.

Haydon PG (2001) GLIA: listening and talking to the synapse. Nat Rev Neurosci 2:185-193.

Hayworth CR, Moody SE, Chodosh LA, Krieg P, Rimer M, Thompson WJ
(2006) Induction of neuregulin signaling in mouse Schwann cells in vivo mimics responses to denervation. J Neurosci 26:6873-6884.

He X, Yang F, Xie Z, Lu B (2000) Intracellular $\mathrm{Ca}^{2+}$ and $\mathrm{Ca}^{2+} /$ calmodulindependent kinase II mediate acute potentiation of neurotransmitter release by neurotrophin-3. J Cell Biol 149:783-792.

Herrera AA, Qiang H, Ko CP (2000) The role of perisynaptic Schwann cells in development of neuromuscular junctions in the frog (Xenopus laevis). J Neurobiol 45:237-254.

Jahromi BS, Robitaille R, Charlton MP (1992) Transmitter release increases intracellular calcium in perisynaptic Schwann cells in situ. Neuron 8:1069-1077.

Jones LP, DeMaria CD, Yue DT (1999) N-type calcium channel inactivation probed by gating-current analysis. Biophys J 76:2530-2552.

Kang H, Tian L, Thompson W (2003) Terminal Schwann cells guide the reinnervation of muscle after nerve injury. J Neurocytol 32:975-985.

Kennedy I, Coleman RA, Humphrey PP, Levy GP, Lumley P (1982) Studies on the characterisation of prostanoid receptors: a proposed classification. Prostaglandins 24:667-689.

Kidokoro Y, Saito M (1988) Early cross-striation formation in twitching Xenopus myocytes in culture. Proc Natl Acad Sci USA 85:1978-1982.

Ko C-P, Sugiura YS, Feng Z (2007) The biology of perisynaptic (terminal) Schwann cells. In: The biology of Schwann cells: development, differentiation and immunomodulation (Armati PJ, ed), pp 72-99. Cambridge, UK: Cambridge UP.

Koirala S, Qiang H, Ko CP (2000) Reciprocal interactions between perisynaptic Schwann cells and regenerating nerve terminals at the frog neuromuscular junction. J Neurobiol 44:343-360.

Koirala S, Reddy LV, Ko CP (2003) Roles of glial cells in the formation, function, and maintenance of the neuromuscular junction. J Neurocytol 32:987-1002.

Kummer TT, Misgeld T, Sanes JR (2006) Assembly of the postsynaptic membrane at the neuromuscular junction: paradigm lost. Curr Opin Neurobiol 16:74-82.

Kuno M, Gardner P (1987) Ion channels activated by inositol 1,4,5trisphosphate in plasma membrane of human T-lymphocytes. Nature 326:301-304.

Liu GJ, Bennett MR (2003) ATP secretion from nerve trunks and Schwann cells mediated by glutamate. NeuroReport 14:2079-2083

Mars T, Yu KJ, Tang XM, Miranda AF, Grubic Z, Cambi F, King MP (2001) Differentiation of glial cells and motor neurons during the formation of neuromuscular junctions in cocultures of rat spinal cord explant and human muscle. J Comp Neurol 438:239-251.

Mauch DH, Nagler K, Schumacher S, Goritz C, Muller EC, Otto A, Pfrieger FW (2001) CNS synaptogenesis promoted by glia-derived cholesterol. Science 294:1354-1357.

McEvoy M, Cao G, Llopis PM, Kundel M, Jones K, Hofler C, Shin C, Wells DG (2007) Cytoplasmic polyadenylation element binding protein 1-mediated mRNA translation in Purkinje neurons is required for cerebellar long-term depression and motor coordination. J Neurosci, 27:6400-6411.

McKinney RA, Capogna M, Durr R, Gahwiler BH, Thompson SM (1999) Miniature synaptic events maintain dendritic spines via AMPA receptor activation. Nat Neurosci 2:44-49.

Mirsky R, Jessen KR (1999) The neurobiology of Schwann cells. Brain Pathol 9:293-311.

Muja N, DeVries GH (2004) Prostaglandin E(2) and 6-keto-prostaglandin $\mathrm{F}$ (1alpha) production is elevated following traumatic injury to sciatic nerve. Glia 46:116-129.

Murwani R, Hodgkinson S, Armati P (1996) Tumor necrosis factor alpha and interleukin-6 mRNA expression in neonatal Lewis rat Schwann cells and a neonatal rat Schwann cell line following interferon gamma stimulation. J Neuroimmunol 71:65-71.

Nieuwkoop PK, Faber J (1994) Normal table of Xenopus laevis (Daudin): a systematical and chronological survey of development from the fertilized egg till the end of metamorphosis. New York: Garland.

O’Malley JP, Waran MT, Balice-Gordon RJ (1999) In vivo observations of terminal Schwann cells at normal, denervated, and reinnervated mouse neuromuscular junctions. J Neurobiol 38:270-286.

Peng HB, Yang JF, Dai Z, Lee CW, Hung HW, Feng ZH, Ko CP (2003) Differential effects of neurotrophins and Schwann cell-derived signals on neuronal survival/growth and synaptogenesis. J Neurosci 23:5050-5060. 
Poo MM (2001) Neurotrophins as synaptic modulators. Nat Rev Neurosci 2:24-32.

Reddy LV, Koirala S, Sugiura Y, Herrera AA, Ko CP (2003) Glial cells maintain synaptic structure and function and promote development of the neuromuscular junction in vivo. Neuron 40:563-580.

Reist NE, Smith SJ (1992) Neurally evoked calcium transients in terminal Schwann cells at the neuromuscular junction. Proc Natl Acad Sci USA 89:7625-7629.

Reynolds ML, Woolf CJ (1992) Terminal Schwann cells elaborate extensive processes following denervation of the motor endplate. J Neurocytol 21:50-66.

Robitaille R (1998) Modulation of synaptic efficacy and synaptic depression by glial cells at the frog neuromuscular junction. Neuron 21:847-855.

Rochon D, Rousse I, Robitaille R (2001) Synapse-glia interactions at the mammalian neuromuscular junction. J Neurosci 21:3819-3829.

Saitoe M, Schwarz TL, Umbach JA, Gundersen CB, Kidokoro Y (2001) Absence of junctional glutamate receptor clusters in Drosophila mutants lacking spontaneous transmitter release. Science 293:514-517.

Sand O, Chen BM, Grinnell AD (2001) Contribution of L-type $\mathrm{Ca}^{2+}$ channels to evoked transmitter release in cultured Xenopus nerve-muscle synapses. J Physiol (Lond) 536:21-33.

Scherer SS, Salzer JL (1996) Axon-Schwann cell interactions during perpheral nerve degeneration and regeneration. In: Glial cell development: basic principles and clinical relevance (Jessen KR, Richardson WD, eds), pp 165-196. Abingdon, UK: Bios Scientific.

Son YJ, Thompson WJ (1995a) Schwann cell processes guide regeneration of peripheral axons. Neuron 14:125-132.

Son YJ, Thompson WJ (1995b) Nerve sprouting in muscle is induced and guided by processes extended by Schwann cells. Neuron 14:133-141.
Stoop R, Poo MM (1995) Potentiation of transmitter release by ciliary neurotrophic factor requires somatic signaling. Science 267:695-699.

Stoop R, Poo MM (1996) Synaptic modulation by neurotrophic factors: differential and synergistic effects of brain-derived neurotrophic factor and ciliary neurotrophic factor. J Neurosci 16:3256-3264.

Sutton MA, Ito HT, Cressy P, Kempf C, Woo JC, Schuman EM (2006) Miniature neurotransmission stabilizes synaptic function via tonic suppression of local dendritic protein synthesis. Cell 125:785-799.

Tabti N, Poo MM (1991) Culturing spinal cord neurons and muscle cells from Xenopus embryos. In: Culturing nerve cells (Banker G, Goslin K, eds), pp 137-154. Cambridge, MA: MIT.

Thastrup O, Cullen PJ, Drobak BK, Hanley MR, Dawson AP (1990) Thapsigargin, a tumor promoter, discharges intracellular $\mathrm{Ca}^{2+}$ stores by specific inhibition of the endoplasmic reticulum $\mathrm{Ca}^{2+}$-ATPase. Proc Natl Acad Sci USA 87:2466-2470.

Ullian EM, Harris BT, Wu A, Chan JR, Barres BA (2004) Schwann cells and astrocytes induce synapse formation by spinal motor neurons in culture. Mol Cell Neurosci 25:241-251.

Volterra A, Magistretti PJ, Haydon PG (2002) The tripartite synapse: glia in synaptic transmission. Oxford: Oxford UP.

Wan J, Poo M (1999) Activity-induced potentiation of developing neuromuscular synapses. Science 285:1725-1728.

Wyatt RM, Balice-Gordon RJ (2003) Activity-dependent elimination of neuromuscular synapses. J Neurocytol 32:777-794.

Xie ZP, Poo MM (1986) Initial events in the formation of neuromuscular synapse: rapid induction of acetylcholine release from embryonic neuron. Proc Natl Acad Sci USA 83:7069-7073.

Zhang X, Poo MM (2002) Localized synaptic potentiation by BDNF requires local protein synthesis in the developing axon. Neuron 36:675688. 